\title{
The Effectiveness of Periodization of Linear Exercises on the Lop Skills of Young Badminton Players
}

\author{
Suratman ${ }^{1}$, Wahadi ${ }^{2}$ \\ \{suratman@mail.unnes.ac.id ${ }^{1}$, wahadipssi@mail.unnes.ac.id $\left.{ }^{1}\right\}$ \\ Universitas Negeri Semarang, Indonesia ${ }^{1,2}$
}

\begin{abstract}
Training methods that have high effectiveness in improving the lop skills of young badminton players is needed. The power of young badminton players has not yet appeared. This study was to determine the effectiveness of linear periodization on the lop skills. The linear training periodization has the character of continuously increasing without decreasing so that physical readiness is needed. Research methods this research is a quantitative study with an experimental approach using the One-Group Pretest Post test Design to test the effectiveness of linear training periodization in young badminton players. The research shows; 1) There is an increase in the results of lop training using a linear periodization pattern of 0.470 , which means there is a difference between the initial test and the final test. 2) Giving lop training using linear periodization in this study did not significantly affect the lop skills of young badminton players.
\end{abstract}

Keywords: Linear training periodization, lop skills, young badminton player.

\section{Introduction}

The 1992 Olympics increased participation in badminton [8], so that professional badminton players from various non-basic badminton countries emerged. Badminton coaches initiate coaching from the Early Age group / U11, Children / U13, Beginners / U15), Youth / U17), Youth / U19), Adults [7]. That coaching for athletes is to improve skills and maximum achievement [2].

Young badminton players are novice players / U15. Developed players must be able to train hard, have a solid defence, and improve skills [5]. Badminton player skills include hitting techniques, clear / lop, drop shot and smash, and various kinds of service, netting, drive and return service.

The lop stroke is a basic hitting technique that was first introduced to players at the beginning of badminton practice. The skill of making a clear shot is that every return or stroke made from the dominant side of the body from the back of the field to the back of the opponent's field, the shuttlecock will fall in a position not far from the backline and has a high value [6]. The more scores collected, the higher the score of the lop skill of a badminton player.

Exercise is the primary tool to improve the quality of the functioning of the human organ systems, making it easier for athletes to improve their movements [3]. A training load accompanies good training [10]. Training load is a motor stimulus that can be regulated and controlled by coaches and athletes to improve the quality of the various body equipment available. Training in the short and medium-term is regulated in periodization, namely linear periodization [1]. 
Periodization of linear training is a weight training method where the training load is increased gradually, and the load is increased continuously without any decrease. The performance will improve only if the athlete trains to his maximum capacity against the workload, which increases gradually and is progressively more significant than the conditions at hand [4].

According to the American College of Sports Medicine (ACSM), the intensity of aerobic exercise should reach the target zone of $60 \%-90 \%$ of the maximum heart rate (MHR) frequency; this range of area is usually referred to as the Training Zone. The intensity of light exercise reaches 60-69\% MHR, moderate reaches 70\% -79\% MHR, and high reaches $80 \%-89 \% \mathrm{MHR}$. Exercise intensity can be increased by increasing training load, jumping movements, or speeding up exercise movements [9].

The maximum pulse rate can be determined by prediction and measurement, namely 220 minus age [11]. Exercise with intensity while paying attention to reps, sets and rest times. The basis for determining reps, sets and rest is the athlete's age and the maximum number of reps that can be done by the athlete (RM).

This Word document can be used as a template for papers to be published in EAI Core Proceedings. Follow the text for further instructions on text formating, tables, figures, citations and references.

Table 1. The basis for determining reps and sets of exercises

\begin{tabular}{cc}
\hline Repetition & Persentage 1 RM \\
\hline 1 & $100 \%$ \\
2 & $95 \%$ \\
3 & $86 \%$ \\
4 & $78 \%$ \\
5 & $70 \%$ \\
6 & $61 \%$ \\
7 & $53 \%$ \\
\hline
\end{tabular}

Moderate intensity exercise achieves a pulse rate of $70 \%-79 \%$ MHR. The MHR of badminton player U15 is 220-15: 205, meaning that training is identified between 144-162 pulse beats per minute

\section{Methods}

This research is a quantitative study with an experimental approach using the One-Group Pretest Posttest Design to test the effectiveness of linear training periodization in young badminton players. The population and sample of this study were 14 male U15 players of Gatra Semarang Badminton Club in 2020 who were taken purposively. The instrument used was the lop instrument.

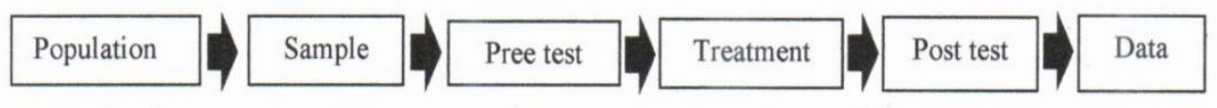

Figure 1. Reseach Method 


\section{Result and Discussion}

The results of lop training with linear periodization were tested using the lop instrument. The test was carried out two times, namely the initial test and the final test. The test results are presented in Table 2

Table 2. Data description from Lop Test Results for U15 Players

\begin{tabular}{cccc}
\hline & Sample & Pre-test results & Post-test results \\
\hline & x1 & 34 & 36 \\
x2 & 23 & 31 \\
x3 & 27 & 18 \\
x4 & 18 & 28 \\
x5 & 32 & 23 \\
x6 & 20 & 23 \\
& x7 & 29 & 29 \\
& x8 & 34 & 33 \\
& x9 & 26 & 26 \\
& x10 & 29 & 27 \\
& x11 & 21 & 33 \\
Total & x12 & 22 & 25 \\
& 12 & 315 & 332 \\
\hline
\end{tabular}

After getting an overview of the data, then the data is processed to produce a statistical picture; the results are as follows:

Table 3. Descriptive Statistics

\begin{tabular}{lccccc}
\hline & N & Minimum & Maximum & Mean & Std. Deviation \\
\hline Pre_Lob & 12 & 18,00 & 34,00 & 26,2500 & 5,49587 \\
Pos_Lob & 12 & 18,00 & 36,00 & 27,6667 & 5,10496 \\
Valid N (listwise) & 12 & & & & \\
\hline
\end{tabular}

The statistical description table, a prerequisite test is then carried out, which includes; 1) Normality test data

The prerequisite for analysis is that the data distribution must be expected, so first, the expected level of the data is tested using the Kolmogorov-Smirnov Goodness of Fit Test assisted by a computer program. The summary of the results of the analysis of the normality test can be seen in Table 4. 
Table 4. Summary of Normality Test Results - Kolmogorov-Smirnov Test

\begin{tabular}{llcc}
\hline & & Pre_Lob & Pos_Lob \\
& $\mathrm{N}$ & 12 & 12 \\
\hline Normal Parameters ${ }^{\mathrm{a}, \mathrm{b}}$ & Mean & 26,2500 & 27,6667 \\
& Std. Deviation & 5,49587 & 5,10496 \\
\multirow{2}{*}{ Most Extreme Differences } & Absolute & 0,140 & 0,102 \\
& Positive & 0,140 & 0,070 \\
& Negative & $-0,108$ & $-0,102$ \\
Test Statistic & & 0,140 & 0,102 \\
Asymp. Sig. (2-tailed) & & $.200^{\mathrm{c}, \mathrm{d}}$ & $.200^{\mathrm{c}, \mathrm{d}}$ \\
\hline
\end{tabular}

a. Test distribution is Normal.

b. Calculated from data.

c. Lilliefors Significance Correction.

d. This is a lower bound of the true significance.

Table 4 shows that the Kolmogorov-Smirnov Z significance for the pre-test is obtained Z2 count 0.140 with a probability of 0.200 , and the final test result (post-test) is obtained $\mathrm{Z} 2$ count 0.102 with a probability of 0.200 . Both of them show probability numbers greater than $(>)$ the level of significance $(\alpha=0.05)$ so that the data distribution does not deviate from its normal curve, or it can be stated that the data is normally distributed.

\section{2) Variance Homogeneity Test}

The homogeneity test is used to determine the homogeneity of the data or not from all research variables. The homogeneity test was calculated using the Chi-Square test. The data is said to be homogeneous if the significance is more significant than 0.05 . The results of the homogeneity test can be seen in Table 5 .

Table 5. Homogeneity test of variance

\begin{tabular}{lcc}
\hline & Pre_Lob & Pos_Lob \\
\hline Chi-Square & $1.333^{\mathrm{a}}$ & $1.333^{\mathrm{a}}$ \\
df & 9 & 9 \\
Asymp. Sig. & 0,998 & 0,998 \\
\hline
\end{tabular}

The results of the homogeneity test showed that the significance value for the initial test (pre-test) was obtained $\mathrm{X}^{2}$ count 1.333 with a probability of 0.998 , and the post-test results obtained $X^{2}$ count 1.333 with a probability of 0.998 . Both of them have a significance of $n>$ 0.05 , and it can be concluded that the initial test and the final test have a homogeneous data variance so that it can be continued with a parametric test.

3) Hypothesis testing

The effect test uses the t-test - the amount of $t$ can be compared with the t table. If $t$ count $\geq t$ table, then the hypothesis is accepted; otherwise, the hypothesis is rejected if $t$ count $\leq t$ table. The summary of the test results is presented in the following table, starting from the paired 
sample statistics, paired sample correlations and paired sample test. More details can be parsed based on the following table 6 :

Tabel 6. Paired Samples Statistics

\begin{tabular}{llclcc}
\hline & & & & Std. Error \\
& & Mean & N & Std. Deviation & Mean \\
\hline Pair 1 & Pre_Lob & 26,2500 & 12 & 5,49587 & 1,58652 \\
& Pos_Lob & 27,6667 & 12 & 5,10496 & 1,47367 \\
\hline
\end{tabular}

Based on the table of paired samples statistics, it is known that the results of the sample loop have increased, from 26.2500 to 27.6667

Tabel 7. Paired Samples Correlations

\begin{tabular}{llccc}
\hline & & N & Correlation & Sig. \\
\hline Pair 1 & Pre_Lob \& & 12 & 0,237 & 0,459 \\
& Pos_Lob & & & \\
\hline
\end{tabular}

Based on table 7, it is known that the correlation between the initial test and the final test is 0.237 so that there is a significant relationship.

Tabel 8. Paired Samples Test

\begin{tabular}{|c|c|c|c|c|c|c|c|c|c|}
\hline & \multicolumn{5}{|c|}{ Paired Differences } & $\mathrm{t}$ & $\mathrm{df}$ & \multirow[t]{3}{*}{$\begin{array}{l}\text { Sig. (2- } \\
\text { tailed) }\end{array}$} \\
\hline & & \multirow[b]{2}{*}{ Mean } & \multirow{2}{*}{$\begin{array}{c}\text { Std. } \\
\text { Deviation }\end{array}$} & \multirow{2}{*}{$\begin{array}{l}\text { Std. Error } \\
\text { Mean }\end{array}$} & \multicolumn{2}{|c|}{$\begin{array}{l}\text { 95\% Confidence } \\
\text { Interval of the } \\
\text { Difference }\end{array}$} & & & \\
\hline & & & & & Lower & Upper & & & \\
\hline $\begin{array}{c}\text { Pair } \\
1\end{array}$ & $\begin{array}{c}\text { Pre_Lob } \\
- \\
\text { Pos_Lob }\end{array}$ & $-1,41667$ & 6,55686 & 1,89280 & $-5,58270$ & $\begin{array}{c}2,749 \\
36\end{array}$ & $-0,748$ & 11 & 0,470 \\
\hline
\end{tabular}

The table of paired samples test, it can be seen that the significance (2-tailed) is 0.470 greater than 0.05 . So it can be concluded that there is a difference between the initial test and the final test of the badminton player U15 PB Gatra Semarang. Furthermore, to determine the effect of the stroke pattern training on the lop, compare the t count and table. From table 8, it is known that the t-test results are 0.748 while the table with df 11 with a significance level of $5 \%$ is obtained a number of 2.201 , meaning that $t$ is smaller than the $t$ table, so it can be said that the hypothesis is rejected, meaning that lop training using linear periodization is not given a significant influence on the results of lop badminton player U15 of Gatra Semarang Badminton Club.

The results of this study illustrate that there is a difference between the pretest and post-test results of the lop hit; that is, there is an increase of 0.470 . The t-test result is $0.748 \leq \mathrm{t}$ table which is 2.201 , and the hypothesis proposed in this study is rejected. So it can be stated that 
there is no effect of giving lop training using linear periodization on the lop skills of young badminton players. This happens can be analyzed on the factors that influence it.

\section{Conclusion.}

Based on the results of the research data, it can be concluded that

1) There is an increase in the results of lop training using a linear periodization pattern of 0.470 , which means there is a difference between the initial test and the final test.

2) Giving lop training using linear periodization in this study did not significantly affect the lop skills of young badminton players.

\section{References}

[1] Fleck, S. Non-Linear Periodization for General Fitness \& Athletes. Journal of Human Kinetics, 29A (Special-Issue). DOI: 10.2478 / v10078-011-0057-2. 2011

[2] Harsono. Sports Coaching Theory and Methodology. Bandung: PT. Rosdakarya youth. 2017

[3] Ismoyo F. The Effect of Ladder Drill Variation Training on Dribbling Ability, Agility, and Coordination in Athletes aged 12-13 Years. Journal of Sports Science. URL: http://eprints.uny.ac.id/id/eprint/14377. 2014

[4] Lau B. Principles of Exercise. Muhammadiyah Sukabumi University. Sukabumi Indonesia https://www.researchgate.net/institution/_Universitas_Muhammadiyah_Sukabumi. 2018

[5] Lie I and Timur M. Skills Needed by Indonesian Badminton Athletes in the Future. https://pbdjarum.org/berita/diluar-arena/1/4fb6f95d67cccf60ed/keampilan-yang-dibentuk-atletbulutangkis-indonesia-di-masa-depan\#gref. 2016

[6] Ni'mah, IT \& Deli M. The Smart Badminton Book. Jakarta: Grace. 2017

[7] PB.PBSI. Practical Guidelines for Playing Badminton. Jakarta: PB.P.B.S.I Jakarta. 2011

[8] Phomsoupha M and Laffaye G. The Science of Badminton: Game Characteristics, Anthropometry, Physiology, Visual Fitness and Biomechanics. Sports Med. 2015 Apr; 45 (4): 473-95. DOI: 10.1007 / s40279-014-0287-2. 2015

[9] Ratmawati Y. Moderate Intensity Aerobic Exercise with Low Cholesterol Diet is Better in Improving Cognitive Than Mild Intensity in Metabolic Syndrome Sufferers. In Pollock, M.L \& Wilmore, J.H. Exercise in health and disease. Evaluation and Prescription for Prevention and Rehabilitation 2nd. Ed Saunders, Philadelphia. 2013

[10] Sukadiyanto. Introduction to Theory and Methodology of Physical Training. Yogyakarta: Yogyakarta State University.2010

[11] Sulastri R, Mariati S and Syamsuar. The Effect of Jogging Exercise with a Treadmill on Resting Pulse of Mothers of the Fitness Center Members of the Indonesian Foundation. Journal of Sports $\begin{array}{llllll}\text { Science and Physical Education. } & \text { Vol. } & 18 & \text { No. } & 1 .\end{array}$ http://sportscience.ppj.unp.ac.id/index.php/jss/index. 2018. 